\title{
PRIMARY REPLACEMENT OF THE FRACTURED RADIAL HEAD WITH A METAL PROSTHESIS
}

\author{
D. J. KNIGHT, L. A. RYMASZEWSKI, A. A. AMIS, J. H. MILlER \\ From Glasgow Royal Infirmary, Scotland and Imperial College, London, England
}

Compression testing of cadaver specimens showed that excision of the radial head allowed proximal radial displacement. The insertion of a metallic radial head restored normal mechanics, while a silicone rubber implant did not.

We reviewed 31 of 36 comminuted fractures of the radial head, 21 associated with dislocation or ulnar fracture, which had been treated by primary replacement with a Vitallium prosthesis. At a mean follow-up of 4.5 years, there was reliable restoration of stability and prevention of proximal radial migration. There had been no dislocations or prosthetic failures, but two implants had been removed for loosening. The prosthesis is recommended for use as a spacer to stabilise the elbow after severe injuries while the soft tissues heal.

J Bone Joint Surg [Br] 1993; 75-B:572-6.

Received 1 September 1992; Accepted after revision 3 February 1993

Replacement of the radial head has a controversial role in the acute management of comminuted fractures of the radial head. Excision of the head can give good longterm results (Morrey, Chao and Hui 1979; Goldberg, Peylan and Yosipovitch 1986; Coleman, Blair and Shurr 1987), but may be associated with persistent elbow or wrist pain, cubitus valgus, and proximal radial migration (McDougall and White 1957; Taylor and O'Connor 1964; Mikic and Vukadinovic 1983). Prosthetic replacement has been recommended to prevent these problems,

D. J. Knight, FRCS G, FRCS Ed(Orth), Registrar

L. A. Rymaszewski, MSc, FRCS, FRCS Ed, Consultant Orthopaedic Surgeon

J. H. Miller, FRCS Ed, FRCS G, formerly Consultant Orthopaedic and Accident Surgeon

Glasgow Royal Infirmary, Glasgow G4 0SF, UK.

A. A. Amis, PhD, CEng, MIMechE, Senior Lecturer in Mechanical Engineering

Biomechanics Section, Imperial College of Science, Technology and Medicine, Exhibition Road, London SW7 2BX, UK.

Correspondence should be sent to $\operatorname{Dr}$ A. A. Amis.

(C) 1993 British Editorial Society of Bone and Joint Surgery $0301-620 \mathrm{X} / 93 / 4606 \$ 2.00$ improve stability, and allow early movement (Speed 1941 ; Cherry 1953; Swanson 1973).

Most reports of replacements of the radial head have included relatively few patients and only a short followup. Different materials have been used, but silicone rubber (Swanson, Jaeger and La Rochelle 1981) is probably the most popular, despite reports of fractures (Mayhall, Tiley and Paluska 1981; Morrey, Askew and Chao 1981) and sensitivity reactions (Gordon and Bullough 1982; Worsing, Engber and Lange 1982).

Amis et al (1979) showed that the radial head can transmit large forces, and Morrey et al (1981) found that replacement with silicone rubber had no objective functional advantage over simple excision. Carn et al (1986) demonstrated that silicone rubber compressed easily under physiological forces and transferred minimal load to the capitellum, possibly accounting for the progressive capitellar osteoporosis noted by Mackay, Fitzgerald and Miller (1979). Pribyl et al (1986) found that an acrylic implant resisted valgus angulation better than the softer silicone rubber. Harrington and Tountas (1981) reported the successful use of a titanium implant in 15 patients, and recommended its use when stability was poor after excision of the radial head.

These reports suggest that there may be a role for a radial head prosthesis made of a stiffer material than silicone rubber; we describe the development and clinical trial of a Vitallium prosthesis (Howmedica (UK), London, UK).

\section{MATERIALS AND METHODS}

Implant development. Based on the measurement of 100 normal radiographs (Amis et al 1977) implants were designed in three diameters, with two thicknesses of radial head for each diameter. They were made for use without bone cement, having a pattern of grooves cast into the junction of the head and stem to allow the predominantly axial compressive loading to produce interlock (Fig. 1). The radius of the proximal rim of the head was larger than the anatomical radius to ensure that its edge would not dig into the capitellar cartilage.

The cleaned distal humerus and proximal radius of four fresh cadaver joints were mounted in a compression testing machine at $90^{\circ}$ flexion (Fig. 2) using steel holders with bone cement. The radius was mounted below the 
moving crosshead of the test machine with its head centred on the load axis. The humeral tray was placed on two pairs of rollers between flat plates; this allowed selfcentring of the radial head on the capitellum as load was applied. The radius was loaded axially with up to $1 \mathrm{kN}$ force at a speed of $5 \mathrm{~mm}$ per minute, producing a load

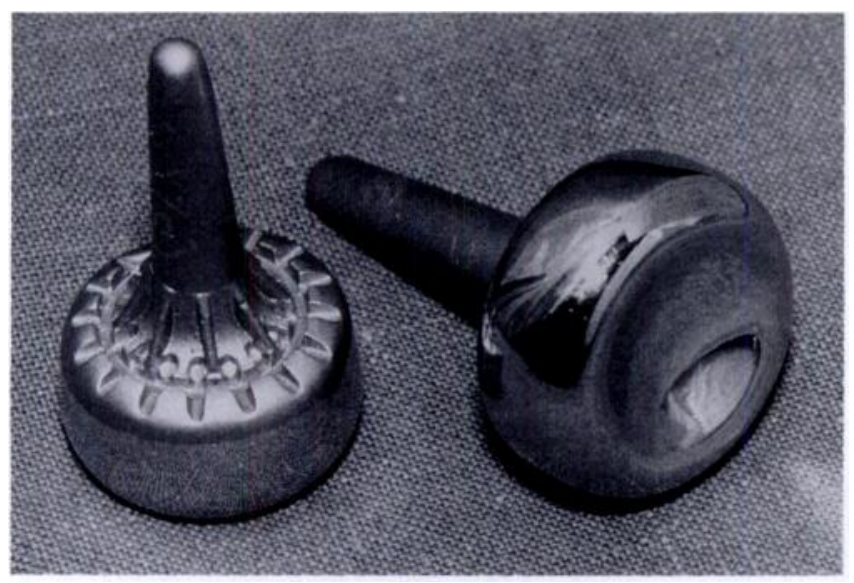

Fig. 1

The Vitallium radial head prosthesis, with an intramedullary stem and a cast pattern of ribs and grooves at the junction between head and stem. This is made in three diameters, with two head thicknesses for each diameter.

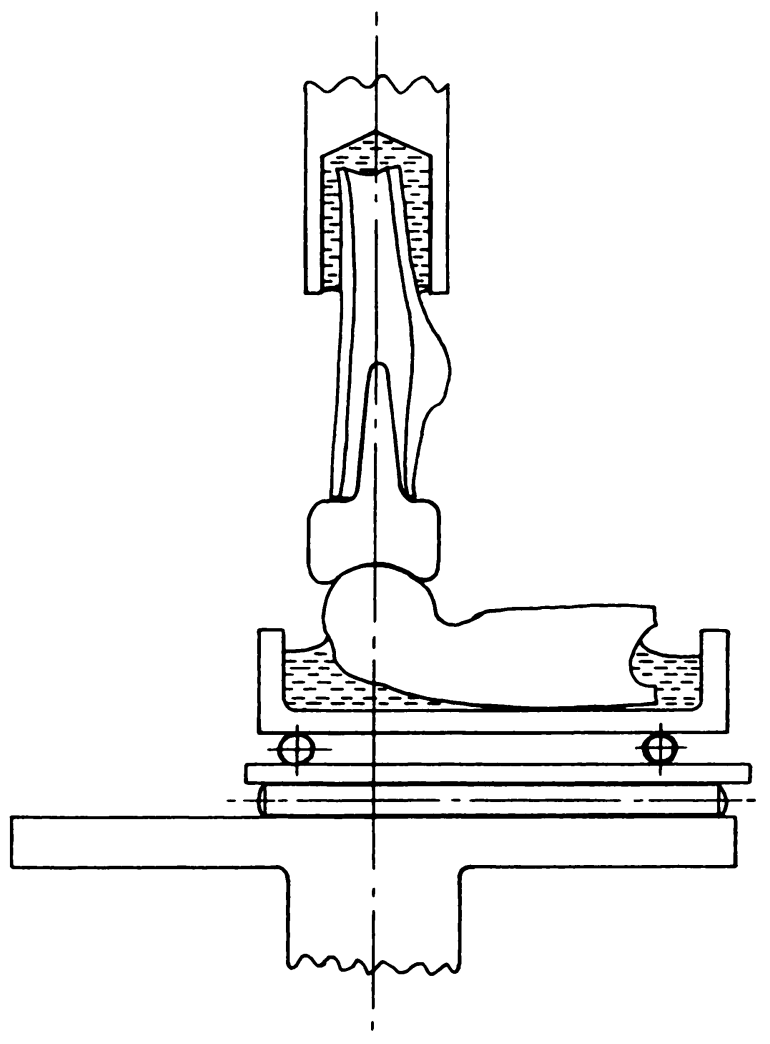

Fig. 2

Diagram of a compression test for the radiohumeral joint. The rollers beneath the humeral tray allow self-centring of the joint under load. versus displacement curve. This procedure was repeated after replacement of the radial head by Vitallium and then two sizes of silicone rubber implants (Silastic: Dow Corning, Reading, UK), using this order because the latter stems were larger. The resulting graphs (Fig. 3) showed that metallic implants gave virtually normal behaviour, whereas silicone rubber implants were deformed easily, allowing proximal radial migration under load.

To study the contribution of the interosseous membrane to the resistance of proximal radial migration, two embalmed arms were tested, after the hand had been removed at the radiocarpal joint and replaced by a steel ball mounted distal to the radius by a cemented intramedullary stem. The radial head was removed through a lateral incision and the soft tissues were removed from the posterior aspect of the humerus which was then mounted as in Figure 2. All other soft tissues and the ulna were undisturbed. The interosseous membrane was tested by loading the distal radius in a proximal direction via the ball joint at $5 \mathrm{~mm} / \mathrm{min}$, so that secondary movements were not prevented, and force versus deflection curves were recorded. Figure 3 shows that the interosseous membrane gave intermediate bone displacement behaviour, being stiffer than silicone rubber radial heads and more compliant than natural and Vitallium heads.

Surgical technique. The implants were inserted as soon as possible, within 24 hours of the injury in all but two cases, by a number of orthopaedic surgeons. Kocher's lateral approach was normally used, with Boyd's posterolateral approach when the olecranon had also been fractured. Fragments of the radial head were removed and the annular ligament was divided if necessary. The end of the radial neck was preserved as far proximally as the fracture allowed, since excessive bone removal would have prevented load transmission through the implant. The neck was reamed to an undersized stem cavity, and the correct size of implant was chosen by trial articulation, using radial head sizers without stems. The prosthesis was then driven into position, uncemented, and the annular ligament was sutured if this was possible. Postoperatively, the elbow was mobilised within two weeks.

Clinical trial. A total of 36 consecutive patients were treated over a 6-year period, and 31 were reviewed: two had died of unrelated causes and three were lost to followup. Mean follow-up was 4.5 years ( 2 to 8 ), and there were 12 men and 19 women aged from 21 to 83 years (mean 57), at the time of follow-up. Each patient was reviewed by two of the authors (DJK, LAR) and the results were assessed clinically and radiologically.

Ten patients had an isolated comminuted fracture of the radial head; in addition, eight had a fracture of the olecranon (often extending into the proximal ulna) and 13 had elbow dislocation. Twenty-one patients had sustained their injury in simple falls, nine had fallen from 


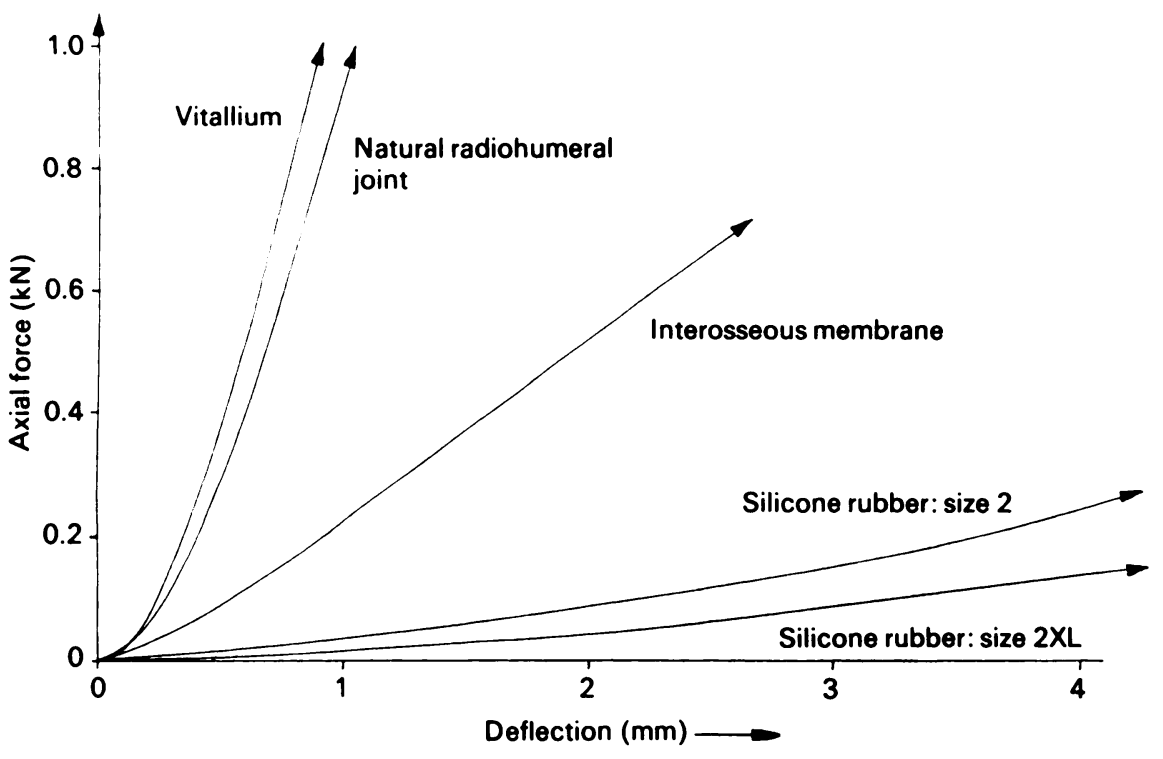

Fig. 3

Mean load-deflection curves for compression tests of the intact radiohumeral joint $(n=4)$, of the interosseous membrane in an embalmed arm after head excision $(\mathrm{n}=$ 4 ), and of the joint after radial head replacement by silicone rubber and Vitallium implants $(n=4)$. At $2 \mathrm{~mm}$ deflection the size 2 silicone rubber head carried only $88 \mathrm{~N}$. The interosseous membrane carried $522 \mathrm{~N}$, or $86 \%$ of the total load.

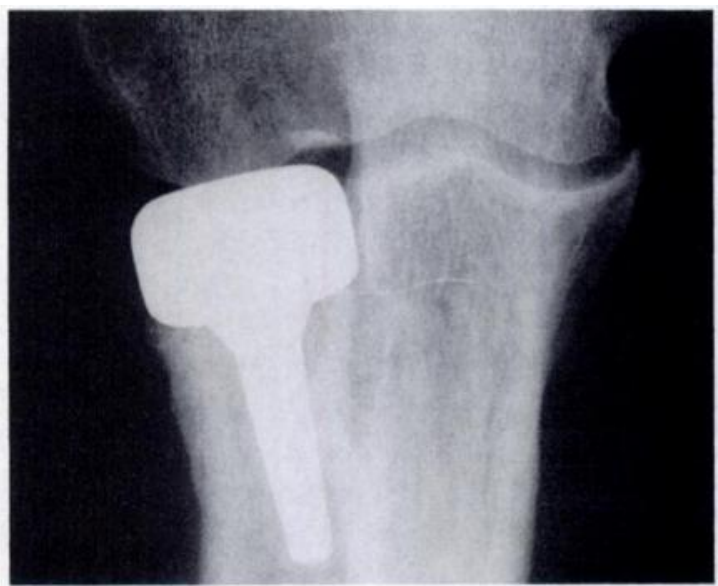

Fig. 4a

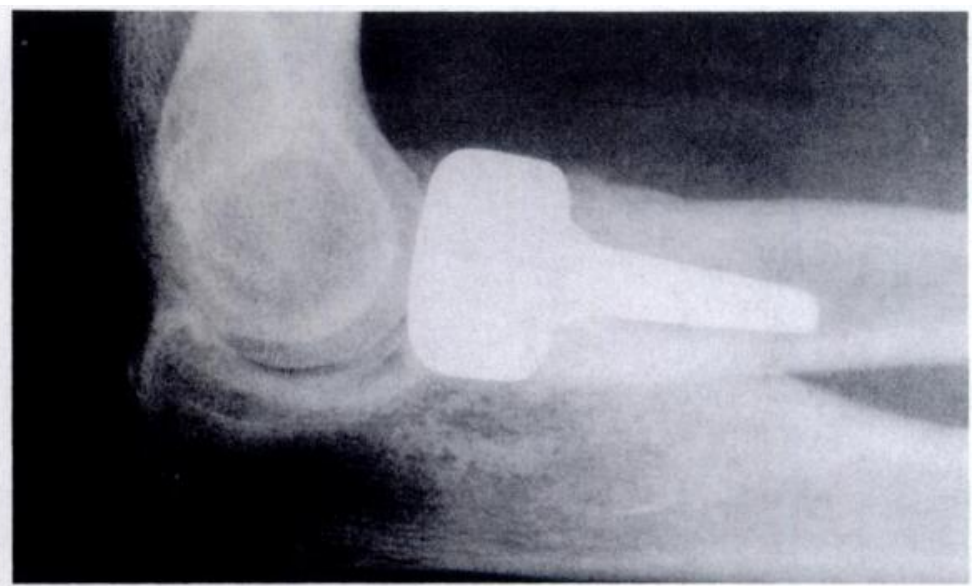

Fig. 4b

Anteroposterior (a) and lateral (b) radiographs of the prosthesis in situ.

a height, and one had been in a road-traffic accident. The dominant arm was affected in 15 of the 31 cases.

\section{RESULTS}

Subjective assessment. At review, 24 of the 31 patients reported little or no elbow pain, six had some aching around the lateral side of the joint, but only with activity. One complained of pain at rest but no cause could be found.

Only two patients had wrist pain with normal activities, apart from an occasional ache. One of these had $10 \mathrm{~mm}$ subluxation of the distal radio-ulnar joint after removal of the prosthesis for loosening, and the other had normal wrist radiographs.

Objective assessment. Ranges of movement were compared with those of the normal limb, using a long-arm goniometer to measure flexion-extension and Patrick's (1946) pendulum goniometer for pronation-supination. The mean flexion deformity was $20^{\circ}\left(0^{\circ}\right.$ to $\left.55^{\circ}\right)$. The mean loss of flexion was $10^{\circ}\left(0^{\circ}\right.$ to $\left.25^{\circ}\right)$; the mean loss of pronation was $10^{\circ}\left(0^{\circ}\right.$ to $\left.30^{\circ}\right)$ and of supination was $10^{\circ}$ $\left(0^{\circ}\right.$ to $\left.60^{\circ}\right)$. One elbow showed moderate valgus laxity, but the patient had no symptoms.

Complications. There were no cases of infection, prosthetic fracture or dislocation. At review two patients had mild ulnar nerve paraesthesia. In two patients the prostheses had been removed for painful loosening; one of these also had a radio-ulnar synostosis which had been treated by the insertion of a silicone rubber sheet. Ten patients reported weakness compared with the normal side or had slightly reduced power on clinical testing by manual resistance to flexion and extension, comparing right and left arms. Grip strength was not assessed.

Radiography. Anteroposterior and lateral radiographs showed radiolucent lines around seven prostheses, but these did not appear to be progressive. We could make no reliable assessment of capitellar erosion or osteoporosis (Fig. 4).

Posteroanterior radiographs of both wrists were compared and revealed subluxation of the distal radio- 
ulnar joint in two patients, in one by $2 \mathrm{~mm}$ and in the other by $10 \mathrm{~mm}$. The patient with symptoms and $10 \mathrm{~mm}$ movement had had the prosthesis removed. Stress radiographs with the fingers clenched showed that muscle contraction did not affect these measurements.

\section{DISCUSSION}

There is no consensus about the treatment of an unstable elbow injury associated with fracture of the radial head. The options include early or delayed excision, reconstruction and replacement. Early excision of the radial head requires immobilisation for several weeks to allow the soft tissues to heal. There is a risk of redislocation and of stiffness. Reconstruction of the radial head is possible only when there are two or three main fragments: this may be technically difficult. Delayed excision of the radial head is sometimes performed several weeks later when necessary. Residual stability may be poor and there is a risk of myositis ossificans after delayed surgery.

For acute replacement of the radial head, the metallic prosthesis offers several advantages and avoids some of the disadvantages of silicone rubber. Its rigidity improves elbow stability when there has been gross softtissue tearing: we had no cases of redislocation. The internal fixation of an associated olecranon or proximal ulnar fracture may be poor because of comminution and osteoporotic bone: the use of a lateral spacer helps to share and balance the forces acting across the elbow, and allows earlier mobilisation. The Vitallium prosthesis was well tolerated, with a low incidence of symptomatic loosening and erosion. It did not break or cause inflammatory reactions.

We therefore recommend the use of this prosthesis as a spacer to aid stability while the bone and soft tissues heal. It can be removed at a later date if symptomatic loosening occurs, but it is usually well tolerated. In the longer term, this rigid implant should prevent proximal radial migration and the consequent valgus angulation of the elbow which has been reported to cause significant symptoms in two-thirds of previous reviews (McDougall and White 1957; Taylor and O'Connor 1964; Mikic and Vukadinovic 1983).

Mechanical tests showed that for a given load, the radius migrated 2.6 times as far proximally after excision of the radial head than when intact, and that the Vitallium implant resisted this. After silicone rubber replacement, the radius still migrated 2.3 times as far as normal, and we believe that deflections would have been larger in fresh forearms, without the stiffening effect of embalming on the interosseous membrane. Figure 3 shows that the interosseous membrane still carried $86 \%$ of the load after replacement with silicone rubber. This explains why Morrey et al (1981) failed to find a functional advantage for silicone rubber replacement over excision alone.

Some of our patients had significant restriction of movement or pain on activity, but this correlated well with the severity of the initial injury. In our series $68 \%$ had dislocations or ulnar fractures or both; such severe injuries would have caused exclusion from those series which have reported generally good results for excision of the radial head.

Undisplaced radial head fractures are always treated conservatively; as the severity of the injury increases, the need for excision of the radial head increases and the controversial question of prosthetic replacement arises.

We have not proved the case for the routine insertion of a prosthesis after resection for an isolated fracture of the radial head: similar results have been reported without the use of an implant. If the elbow is stable in flexion immediately after excision of the radial head, both our study and previous reports suggest that there is no advantage in replacement.

We emphasise that replacement must be carried out early, before soft-tissue contraction causes malalignment of the radial shaft on the capitellum. Late insertion was seen by the senior author (JHM) to cause malarticulation, impingement, and capitellar erosion.

\section{Conclusions}

1) Metallic radial head replacement restores the axial stiffness of the forearm to normal; excision and silicone rubber implants allow abnormal proximal migration under load.

2) A metallic prosthesis has a role in the acute management of severely displaced fractures of the radial head associated with dislocation or ulnar fracture.

3) Replacement of the radial head is not clearly better for an uncomplicated fracture; proof of this would require a prospective randomised trial.

Although none of the authors have received or will receive benefits for personal or professional use from a commercial party related directly or indirectly to the subject of this article, benefits have been or will be received but are directed solely to a research fund, foundation, educational institution, or other non-profit institution with which one or more of the authors is associated.

\section{REFERENCES}

Amis AA, Dowson D, Unsworth A, Wright V, Miller JH. An examination of the elbow articulation with particular reference to variation of the carrying angle. Eng Med 1977; 6:76-80.

Amis AA, Dowson D, Wright V, Miller JH. The derivation of elbow joint forces, and their relation to prosthesis design. J Med Eng Technol 1979; 3:229-34.

Cam RM, Medige J, Curtain D, Koenig A. Silicone rubber replacement of the severely fractured radial head. Clin Orthop 1986; 209: 259-69.

Cherry JC. Use of acrylic prosthesis in the treatment of fractures of the head of the radius. J Bone Joint Surg [Br] 1953; 35-B:70-1.

Coleman DA, Blair WF, Shurr D. Resection of the radial head for fracture of the radial head: long-term follow-up of seventeen cases. $J$ Bone Joint Surg [Am] 1987; 69-A :385-92.

Goldberg I, Peylan J, Yosipovitch Z. Late results of excision of the radial head for an isolated closed fracture. J Bone Joint Surg (Am] 1986; 68-A :675-9. 
Gordon M, Bullough PG. Synovial and osseous inflammation in failed silicone-rubber prostheses: a report of six cases. J Bone Joint Surg [Am] 1982; 64-A :574-80.

Harrington IJ, Tountas AA. Replacement of the radial head in the treatment of unstable elbow fractures. Injury 1981; 12:405-12.

Mackay I, Fitzgerald B, Miller JH. Silastic replacement of the head of the radius in trauma. $J$ Bone Joint Surg [Br] 1979; 61-B:494-7.

Mayhall WST, Tiley FT, Paluska DJ. Fracture of silastic radial-head prosthesis: case report. J Bone Joint Surg [Am] 1981; 63-A : 459-60.

McDougall A, White J. Subluxation of the inferior radio-ulnar joint complicating fracture of the radial head. $J$ Bone Joint Surg [Br] 1957; 39-B:278-87.

Mikic ZD, Vukadinovic SM. Late results in fractures of the radial head treated by excision. Clin Orthop 1983; $181: 220-8$.

Morrey BF, Askew L, Chao EY. Silastic prosthetic replacement for the radial head. J Bone Joint Surg [ $\mathrm{Am}$ ] 1981 ; 63-A :454-8.

Morrey BF, Chao EY, Hui FC. Biomechanical study of the elbow following excision of the radial head. J Bone Joint Surg [Am] 1979; 61-A:63-8.
Patrick J. A study of supination and pronation with especial reference to the treatment of forearm fractures. J Bone Joint Surg 1946; $28: 737-48$.

Pribyl CR, Kester MA, Cook SD, Edmunds JO, Brunet ME. The effect of the radial head and prosthetic radial head replacement on resisting valgus stress at the elbow. Orthopedics 1986; 9:723-6.

Speed K. Ferrule caps for the head of the radius. Surg Gyn Obstet 1941 ; 73:845-50.

Swanson AB. Flexible implant resection arthroplasty in the hand and extremities. St Louis: CV Mosby Co, 1973.

Swanson AB, Jaeger SH, La Rochelle D. Comminuted fractures of the radial head: the role of silicone-implant replacement arthroplasty. J Bone Joint Surg [ Am] 1981 ; 63-A : 1039-49.

Taylor TKF, O'Connor BT. The effect upon the inferior radio-ulnar joint of excision of the head of the radius in adults. $J$ Bone Joint Surg [Br] 1964 ; 46-B:83-8.

Worsing RA, Engber WD, Lange TA. Reactive synovitis from particulate silastic. J Bone Joint Surg [ Am] 1982; 64-A :581-5. 